\title{
STUDY OF MORPHOLOGY, PREVALENCE AND MEAN INTENSITY OF MONOGENEANS INFECTING POND REARED Pangasianodon hypophthalmus (STRIPED CATFISH) IN BESUT, TERENGGANU
}

\author{
SARAH SALEHAH AND FAIZAH SHAROM \\ School of Fisheries and Aquaculture Sciences, Universiti Malaysia Terengganu, \\ 21030 Kuala Nerus, Terengganu, Malaysia. \\ Correspondingauthor:faizah@umt.edu.my
}

\begin{abstract}
This study was conducted to determine the morphology, prevalence and mean intensity of monogeneans on gill filaments of striped catfish Pangasianodon hypophthalmus (Pangasiidae). P. hypophthalmus are important economic fish in Southeast Asia region and predominantly produced in Asian countries such as Malaysia, Bangladesh, Indonesia, Vietnam, Laos, China and Cambodia through aquaculture. Thirty fish were sampled from an earthen pond located in Kuala Besut, Terengganu, in the period from January to February, 2018. The monogenean parasites were removed from the gill filaments and counted. For the morphological study, the extracted monogeneans were mounted on a slide by using drop of ammonium picrate-glycerin (APG) and then were observed under the Compound Advanced Research Microscope. The drawing was done with the aid of lucida camera attached to compound microscope. The monogenean parasite was identified as Thaparocleidus $\mathrm{sp}$ based on the characteristics of the morphology and morphometrics of the parasite, which did not differ significantly from the previous descriptions of the same species discovered in other geographic locations. The prevalence and mean intensity levels were $100 \%$ and 106.07 parasites per fish, respectively. The monogenean parasites discovered throughout this examination were recorded and the data obtained was summarized.
\end{abstract}

Keywords: Parasite, Thaparocleidus sp, monogenea, P. hypophthalmus, freshwater fish, pond culture

\section{Introduction}

According to a study by Hudson et al., in (2006), a variety of parasites can be an indication of ecosystem health. The influence of parasites on fish health can be seen through physical, mechanical and reproductive harm they cause. When it comes to fish health evaluation, the role of parasites in their host(s) is frequently overlooked (Iwanowicz, 2011). This is true where there is minimal or information about the species on baseline data of parasite ecology and diversity (Thompson et al., 2010).

Among them, one group that is well-known but has not yet been fully explored is the monogenean parasites. During recent years, plenty of attention has been paid to obtaining more details on the ecology of monogeneans. These parasitic ectoparasites are not only known for their captivating life cycle, morphology and their perplexing relationships with metazoan groups, but also for being pathogens to fish, especially in fisheries and aquaculture farms.
An awareness in the dynamics of monogenean infection may aid in reducing the loss of fish due to the parasitic diseases (Lim et al., 2016). Whether in the wild or in aquaculture farms, parasitic monogeneans can pose real danger to the fish (Kearn, 2011). So far, monogeneans are the most hostile parasites infecting farmed fish. They are known to infect the gills of their hosts. The infected gills will lead to several problems, for instance difficulty in breathing and problem in respiratory function. The overloading infection may lead to lethargy and result in huge loss of fish (Snieszko \& Axelord, 1980).

Especially in the aquaculture industry, these parasitic worms are famous for invading the culture species, such as the striped catfish Pangasianodon hypophthalmus. P. hypophthalmus are freshwater catfish species that are widely cultured and are one of the productive culture species especially in the Southeast Asia (FAO, 2010). According to Pariselle et al., (2001a; 2004; 2006), one of the monogenean group Thaparocleidus spp has been reported to belong to the family of freshwater catfish. Given the importance of maintaining the fish health, especially by minimizing monogenean parasitic infections, it is necessary to 
conduct research to determine the level of parasitic infections of Thaparocleidus sp which invade the $P$. hypophthalmus.

This study investigates monogenean infection affecting freshwater fish in an earthen pond in $\mathrm{Kg}$ Aloi Peroi, Kuala Besut, Terengganu (Pangasianodon hypophthalmus), mainly because of their economic importance as food fish to the local people and to the ecosystem itself. On top of that, this study focuses on providing more detailed information about monogenean infection since there is a lack of reports on this parasite affecting pond-cultured $P$. hypophthalmus in Malaysia. The present study will provide more knowledge on monogenean infection on $P$. hypophthalmus. Additionally, the study of the morphology, prevalence and mean intensity of the parasitic monogeneans can provide some new information for future use by the researchers and communities.

\section{Materials and Method Sample Collection}

A total 30 samples of striped catfish (Pangasianodon hypophthalmus) were obtained from the earthen pond by fishing. The live catch of $P$. hypophthalmus were kept in aerated aquarium and brought to the laboratory for further investigation. The fish samples were killed by using 'pithing' method (Faizah, 2012). This method involved cutting the central nervous system below the head of the fish using a sharp scalpel or pointed needle to damage the nerve cord. The samples were measured to find the length and weight by using a ruler and electronic balance scale respectively. The obtained data were then recorded on the sampling data sheet. Then the fish were dissected using dissecting set. By using a sharp pair of scissors, the fish operculum was cut away to expose the gills. The gill arches were removed carefully and placed into a petri dish. The presence of the monogeneans on each gill was counted with the aid of dissecting microscope that was connected to Dino-Eyepiece USB Camera.

\section{Fixing, Staining and Mounting}

The extracted monogeneans were fixed in $70 \%$ ethanol. The fixed monogeneans were removed and placed on top of microscope slide. With the aids of dropper and dissecting needles, the mucus was removed from the monogeneans and all the excess water was carefully detached from the slide. Few drops of ammonium picrate-glycerin (APG) then were added on to the monogeneans and left soaked for a few second. Excess of APG was absorbed by placing a piece of tissue at the edge of the slide. A coverslip was gently placed on top of the monogeneans to avoid formation of air bubbles. Permanent attachment of the coverslip was done by adding nail polish at each edge of the coverslip. The mounted specimens were observed under compound microscope.

For identification, the morphology of different parts was noted and images were captured by using Advanced Research Compound Microscope (Nikon Eclipse 80i). The measurement of the specimens was obtained using ImageJ software and the drawing was done with the aid of lucida camera. The measurement of the monogeneans and their components are in micrometers (Faizah, 2012).

\section{Calculation of Prevalence and Mean Intensity of Parasites}

The formula for the calculation of prevalence and mean intensity of parasites followed Margolis et al., (1982) and Bush et al., (1997).

$$
\begin{aligned}
& \text { Prevalence } \quad=\frac{\text { Number of infected host }}{\text { Number of examined host }} \times 100 \\
& \text { Mean Intensity }=\frac{\text { Number of parasites found }}{\text { Number of infected host }}
\end{aligned}
$$

\section{Parasite Morphometry}

The mounted monogenean samples were measured and identified based on the variables provided by Pariselle $e t$ al., (2006). Morphometric measurements in micrometer $(\mu \mathrm{m})$ obtained from four mounted monogeneans were recorded. Identification of the parasitic worms follows the appearance and fine structure of sclerotized parts of the monogenean haptor (attachment) (Ergens, 1981; Pariselle et al., 2001a; 2004; 2006).

\section{Results and Discussion}

\section{Taxanomic summary}

Kingdom

Phylum

Subphylum

Order

Family

Genus

Host type

Site of infections

\author{
Animalia \\ Platyhelminthes \\ Monophysthocotylea \\ Dactylogyridea \\ Dactylogyridae \\ Thaparocleidus sp \\ P. hypophthalmus \\ Gill
}


Referring to Pariselle et al., (2001; 2002; 2004), the parasite species characterized belong to Genus Thaparocleidus sp., which are included under Family Dactylogyridae. The monogenean species found have morphological resemblance with Thaparocleidus sp that infect $P$. pangasius in Bangadesh, India and P.hypopthalmus in Chendrawasih, Surabaya, Indonesia. (Pariselle et al., 2001; Anshary \& Talunga, 2013).

Table 1: Measurements of Thapalocleidus sp

\begin{tabular}{|c|c|c|c|c|}
\hline \multirow{2}{*}{ Structures/ Components } & \multirow{2}{*}{ Variable } & \multicolumn{2}{|c|}{ Range } & \multirow{2}{*}{ Mean $(\mu m)$} \\
\hline & & $\operatorname{Min}(\mu m)$ & $\operatorname{Max}(\mu m)$ & \\
\hline \multirow{2}{*}{ Body } & Length, $\mathrm{x}$ & 521 & 557.3 & 545.2 \\
\hline & Width, w & 81.2 & 89.4 & 84 \\
\hline \multirow[t]{2}{*}{ Copulatory organ } & Length, $\mathrm{x}$ & 64 & 79 & 72 \\
\hline & Total length, a & 63.2 & 65.6 & 64.4 \\
\hline \multirow[t]{2}{*}{ Dorsal gripus (DG) } & Shaft length, b & 49.2 & 53.8 & 52 \\
\hline & Root length, c & 21 & 23.2 & 22 \\
\hline \multirow{2}{*}{ Dorsal transverse bar (DB) } & Length, $\mathrm{x}$ & 21.5 & 26 & 23.5 \\
\hline & Width, w & 3.1 & 3.4 & 3.4 \\
\hline \multirow{2}{*}{ Cuneus (C) } & Length, $\mathrm{x}$ & 30.7 & 35.3 & 33 \\
\hline & C width, w & 9 & 10.4 & 9.2 \\
\hline \multirow{3}{*}{ Ventral gripus (VG) } & Total length, $d$ & 20.3 & 21.6 & 20.9 \\
\hline & Shaft length, e & 15.5 & 17.3 & 16.4 \\
\hline & Root length, $\mathrm{f}$ & 12.6 & 15 & 13.8 \\
\hline \multirow{2}{*}{ Ventral transverse bar (VB) } & Length, $\mathrm{x}$ & 34.7 & 39 & 36.8 \\
\hline & Width, w & 6.2 & 7 & 6.7 \\
\hline
\end{tabular}

Thaparocleidus sp (Figure 1) are characterized by the presence of two pairs of eyespots and pharynx at the anterior section (Figure 2A) of the parasitic worms. At the posterior region (Figure 2B), they have two pairs of anchors-dorsal anchor and ventral anchor. At dorsal anchor (Figure 3A), the dorsal gripus is equipped with cuneus and connected by dorsal transverse bar. The ventral anchor (Figure 3B) has a pair of ventral gripus which is connected by ventral transverse bar.

The monogenean body is elongated with blunt anterior and posterior regions measuring length $\mathrm{x}=545.2$ $\mu \mathrm{m}$ (range $521-557.3 \mu \mathrm{m}$ ) and $\mathrm{w}=84 \mu \mathrm{m}$ (range 81.2 $-89.4 \mu \mathrm{m})$ wide. The anterior parts of the monogenean have two pairs of eyespots and pharynx. The anterior pair of eyespots is smaller than the posterior pair. The pharynx is spherical in shape.
The copulatory organ of these monogeneans is thin coillike shape measuring $\mathrm{x}=72 \mu \mathrm{m}$ (range $64-79 \mu \mathrm{m}$ ). For the haptor part, there are two pairs of anchor which is the dorsal and ventral anchor. For dorsal anchor region, the measurement for dorsal gripus a, b and c are $64.4 \mathrm{um}$ (range $63.2-65.6 \mu \mathrm{m}), 52 \mu \mathrm{m}$ (range $49.2-53.8 \mu \mathrm{m}$ ) and $22 \mathrm{um}$ (range $21-23.2 \mu \mathrm{m}$ ), respectively. The pair of dorsal gripus is connected by dorsal transverse bar measuring $\mathrm{x}=23.5 \mu \mathrm{m}$ (range $21.5-26 \mu \mathrm{m}$ ) and $\mathrm{w}=3.4$ $\mu \mathrm{m}$ (range $3.1-3.4 \mu \mathrm{m}$ ). At the anterior end of dorsal gripus is cuneus measuring $\mathrm{x}=33 \mu \mathrm{m}$ (range $30.7-35.3$ $\mu \mathrm{m})$ and $\mathrm{w}=9.2 \mathrm{um}$ (range $9-10.4 \mu \mathrm{m})$. For ventral anchor region, the measurements for dorsal gripus d, e and $f$ are $20.9 \mu \mathrm{m}$ (range $20.3-21.6 \mu \mathrm{m}$ ), $16.4 \mu \mathrm{m}$ (range $15.5-17.3 \mu \mathrm{m}$ ) and $13.8 \mu \mathrm{m}$ (range $12.6-15 \mu \mathrm{m}$ ), respectively. The ventral transverse bar is wide v-shape like with measurement of $x$ and $w-34.7 \mu \mathrm{m}$ and $6.2 \mu \mathrm{m}$, respectively. 


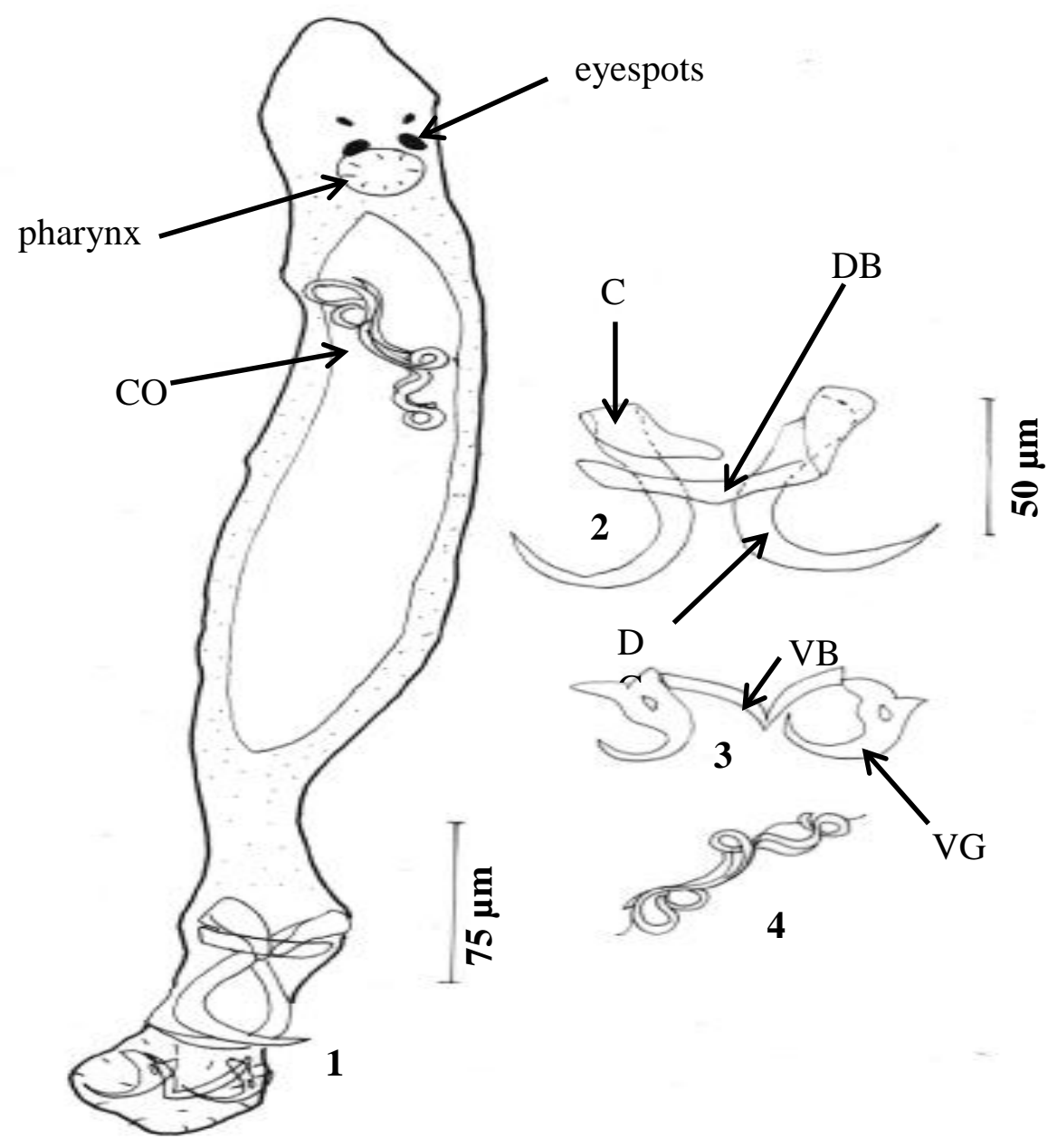

Figure 1: Full drawing of Thaparocleidus sp whith bar scale; 1 - full body drawing from anterior to posterior parts, 2 - dorsal anchor, 3 - ventral anchor and 4 - copulatory organ.
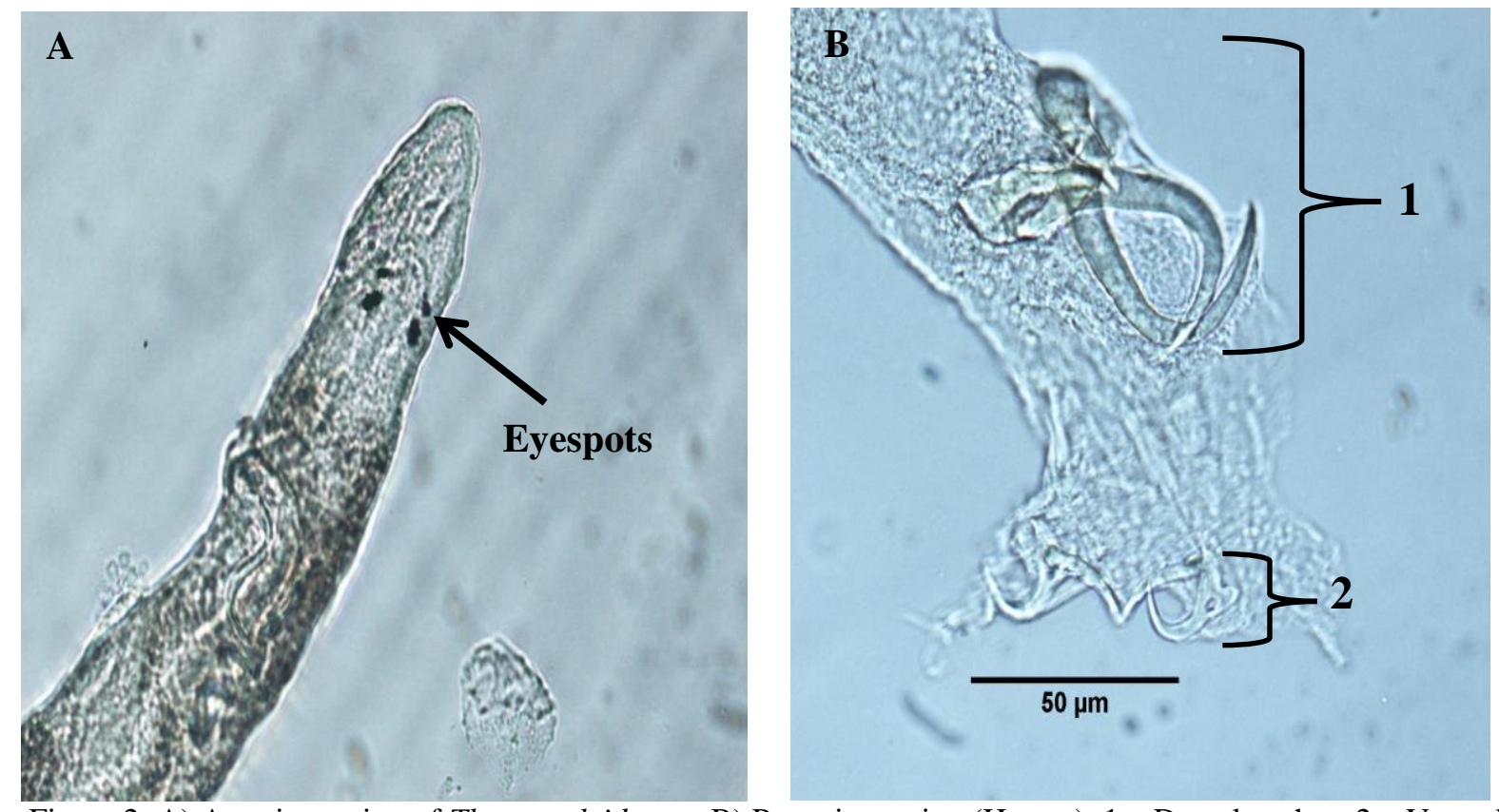

Figure 2: A) Anterior region of Thaparocleidus sp. B) Posterior region (Haptor): 1 - Dorsal anchor, 2 - Ventral anchor. 

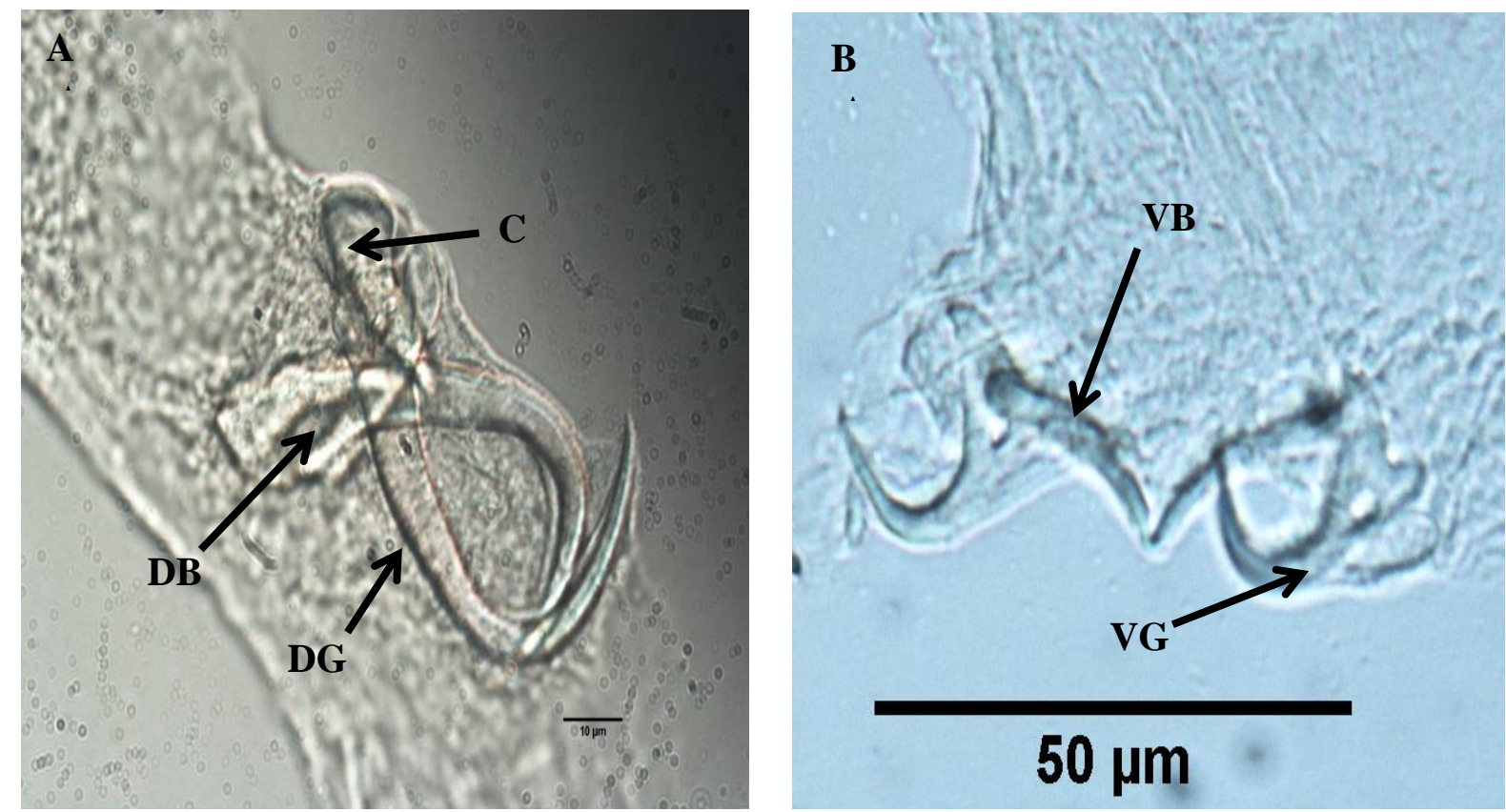

Figure 3: A) Dorsal anchor of the monogenean which consists of cuneus(C), Dorsal gripus (DG) and Dorsal transverse bar (DB). B) The ventral anchor of the monogenean consists of Ventral gripus (VB) and Ventral transverse bar (VB).

\section{Prevalence and Mean Intensity}

For the prevalence of monogeneans, this study found that all the examined host $P$. hypophthalmus, were infected with parasitic monogeneans, indicating that all the cultured fish inside the pond were infected with Thaparocleidus sp. The prevalence and mean intensity calculation were done based on the data recorded from the samples and are presented in Table 2.

Table 2: The prevalence and mean intensity of Thaparocleidus sp in P. hypophthalmus.

\begin{tabular}{cccccc}
\hline Parasite & $\begin{array}{c}\text { No. of } \\
\text { examined } \\
\text { host }\end{array}$ & $\begin{array}{c}\text { No. of } \\
\text { infected host }\end{array}$ & $\begin{array}{c}\text { No. of } \\
\text { parasites } \\
\text { found }\end{array}$ & $\begin{array}{c}\text { Prevalence } \\
(\%)\end{array}$ & $\begin{array}{c}\text { Mean } \\
\text { intensity }\end{array}$ \\
\hline $\begin{array}{c}\text { Monogenea } \\
\text { Thaparocleidus sp }\end{array}$ & 30 & 30 & 3182 & 100 & 106.07 \\
\hline
\end{tabular}


Whether in the wild or in aquaculture industry, fish is also prone to diseases like parasitism. The extent of parasitism in fish varies from slight to harsh based upon the pathogenicity of the causal agent and the intensity of worms affecting the fish. As a result, this is a great threat to the fish industry, causing a decline in fish production, and fish infected by some parasites could be unsuitable for human consumption. Parasites can be divided into two subclasses-ectoparasite and endoparasite. According to Shariff (1984), diseases caused by the ectoparasite spread quickly and may cause more than 50 percent mortality in short period.

Through research and knowledge gained on taxonomy, morphology and parasitic life cycle, precautions can be taken to prevent diseases from occurring. Based on the results obtained throughout this study, the parasitic monogeneans that infected the striped catfish, $P$. hypophthalmus were identified as Thaparocleidus sp. Thaparocleidus sp. are parasitic monogeneans that live as ectoparasites on gills and have a direct life cycle. They attach themselves to their host's bodies using anchors that can be found in haptors (Reed et al., 2009). According to Gusev (1985), the identification of monogenean species is mainly based on the morphology of the haptor (attachment organ) and reproductive organ. The morphology of the haptor is considered useful for parasite determination at the genus level, while the reproductive organ is more suitable for identification at the species level, probably because of its higher rate of change (Pouyaud et al., 2006; Wu et al., 2008b).

According to Pariselle et al. (2001b), several Thaparocleidus species have been reported from Family Pangasiidae in Southeast Asia, namely $P$. pangasius, $P$. kinabatanganensis, $P$. nieuwenhuisii and $P$. rheophilus. They also reported that parasitic monogenean Thaparocleidus sabanensis was found on the gills of Pangasius kinabatanganensis (Roberts \& Vidthyanon, 1991) in Kinabatangan River, Sabah, Malaysia. The Thaparocleidus sabanensis described has some similarity with the species found recently on the gills of $P$. hypophthalmus. The similarity can be seen on morphological characteristic for both monogenean species. However, the size of Thaparocleidus sp found in recent studies was much smaller compared to previous studies. This may be due to the different locations. In addition, a study showed that Thaparocleidus sp infecting the $P$. hypophthalmus in Surabaya, Indonesia (Anshary \& Kalanga, 2013) also displayed great resemblance with the Thaparocleidus sp found recently in terms of the morphological parts for anterior region (granulated eyespots) and posterior region (haptor).

Thaparocleidus are generally gill monogeneans found in siluriform fishes (Cohen \& Anna, 2008; Simkova et al.,
2013). These parasitic worms are extremely host specific, which means mostly all are restricted only to one host species (Kabata, 1970; Rohde, 1979; Poulin, 1992). Pariselle et al., 2006 stated that around 43 species of Thaparocleidus have been reported from Pangasiidae fish. Thus, it can be confirmed that the parasitic monogeneans found on the gills of $P$. hypophthalmus in the earthen pondculture in Kuala Besut are indeed from the Genus Thaparocleidus.

The study area is an earthen pond (21 feet length $\mathrm{x} 16$ feet width with 17000 starting seeds of $P$. hypophthalmus), which commonly receives rainwater and the amount of water is always variable (hinged on the rainfall). Since production, there is no treatment and water exchanging done by the farmer. The P. hypophthalmus vary in size and are fed fish pellet and trash fish once a day.

The prevalent rate of parasitic infections of $100 \%$ indicates that the entire fish population inside the pondculture were attacked by the parasitic Thaparocleidus sp. The parasite's life cycle is closely related to the high level of parasite prevalence since these parasites have a direct life cycle with no intermediary host involved in their life cycle. The eggs hatch into free-swimming larvae and are carried to a new host by water currents and their own ciliated movement (Rohde, 2005). Its prevalence and intensity increase significantly when the parasite life cycle is completed (Ahmed et al., 2007).

Parasites utilize at least two different habitats, one of which is switching between two individual hosts (the ecosystem), and the other being in or on the same host (immediate environment) (Thomas et al., 2002). High density together with poor nutrition of fish also hasten the spread of parasites, in addition to stress factors due to poor water quality, allowing rapidly developing parasites. The area around the pond was also surrounded with overgrown vegetation (Mdegela et al., 2011).

\section{Conclusion}

The parasitic monogeneans that invaded the gills of $P$. hypophthalmus in an earthen pond in Kg. Aloi Peroi, Kuala Besut, Terengganu belong to the genus Thaparocleidus. The morphology parts of the parasites found in the recent study have several similarities with previous studies of monogeneans on the same fish species (Lim et al., 1961; Pariselle et al., 2001a; Anshary \& Kalanga, 2013). Prevalence and mean intensity of Thaparocleidus sp. are relatively high, $100 \%$ and 106.07 , respectively, indicating low frequency of freshwater catfish maintenance. This can endanger the condition of the fish body. The high density triggers the development of parasites in the cultured system and thus may cause economic loss. This study looks at the morphology; perhaps future work can focus on molecular 
studies of the monogeneans and whether the species is the same as the others in previous studies.

\section{Acknowledgements}

I thank my colleagues from School of Fisheries and Aquaculture who provided insight and expertise that greatly assisted the research. Special thanks to Prof. Emeritus Dr. Faizah Binti Shaharom for her assistance throughout this whole research and my fellow labmates for comments that greatly improved the manuscript.

\section{References}

Ahmed, M.S., Iqbal, T., Mahmood, A., Gulzarin, M., \& Abid, M. (2007). Helminth parasites of some freshwater fishes. Punjab University Journal Zoology, 22, p.1-6.

Anshary, H., S., \& Talunga, J. (2013). Infection Level of Parasite Thaparocleidus sp. On Gills of Striped Catfish (Pangasianodon hypopthalmus). Jurnal Perikanan (Journal of Fisheries Sciences), XV(2), 55-61. doi:ISSN: 0853-6384.

Bush, A.O., Lafferty, K.D., Lotz, J. M \& Shostak, A.W. (1997). Parasitology meets ecology on its own terms: Margolis et al. (1982) revisited. Journal of Parasitology, 83, 575-583.

Cohen, S. C., \& Anna K. (2008). New Data on Species of Demidospermus (Dactylogyridae: Monogenea) Parasitizing Fishes from the Reservoir of the Itaipu Hydroelectric Power Station, Parana State, Brazil, with New Synonymies. Revista Brasileira De Parasitologia Veterinária, 17(3), 167-170. doi:10.1590/s198429612008000300011.

Ergens, R. (1981). Nine species of the genus Cichlidogyrus Paperna, (1960) (Monogenea: Ancyrocephalinae) from Egyptian fishes. Folia Parasitologica, 28, 205-214.

Faizah, S. (2012). Fish Parasites of Lake Kenyir, Penisular Malaysia, $1^{\text {st }}$ edition. Penerbit UMT, Universiti Malaysia Terengganu, Terengganu.

FAO, (2010) www.fao.org/fishery/culturedspecies/Pangasius_hypo phthalmus/en

Guimarães, C. F., Mársico, E. T., Monteiro, M. L., Lemos, M., Mano, S. B., \& Junior, C. A. May (2016). The chemical quality of frozen Vietnamese Pangasius hypophthalmus fillets.
Gusev, V. (1985) Identification of Freshwater Fish Parasites, Nauka, Leningrad, Russia

Hudson. P. J., Dobson, A. P., \& Lafferty, K. D. (2006). Is a Healthy Ecosystem one that is rich in parasites?. Trends in Ecology and Evolution, 21(7), 281-285.

Iwanowicz, D. D. (2011). Overview on the effects of parasites on fish health. Report of Leetown Science Center, US Geological Survey, accessible at http://www.lsc.usgs.gov/files/D \%20Iwanowicz\%202011.pdf

Kabata, Z. (1970). Parasitology of fishes, T.F.H. Publications. Inc. Ltd., Hongkong pp. 104-116.

Kearn, G. (2011). Monogeneans the ultimate fish parasites. Biologist, 58, 29-32.

Lim L.H.S. (1961) Silurodiscoides Gussev, (Monogenea : Ancyrocephalidae) from Pangasius sutchi Fowler 1931 (Pangasidae) cultured in Peninsular Malaysia. Raffles Bulletin of Zoology, 38, 55-63.

Lim, S., Ooi, A., \& Wong, W. (2016). Gill monogeneans of Nile tilapia (Oreochromis niloticus) and red hybrid tilapia (Oreochromis spp.) from the wild and fish farms in Perak, Malaysia: Infection dynamics and spatial distribution. SpringerPlus, 5(1). doi:10.1186/s40064016-3266-2

Margolis, L., Esch, G. W., Holmes J. C., Kuris A. M. \& Schad G. A. (1982). The use of ecological terms in parasitology (Report of an Ad Hoc committee of the American society of parasitologists). Journal of Parasitology, 68(1), 131-133.

Mdegela, R. H., Omary, A., Mathew, N. C., \& Nonga, H. E. (2011). Effect of pond management on prevalence of intestinal parasites in Nile Tilapia (Oreochromis niloticus) under small scale fish farming systems in Morogoro, Tanzania. Livestock Research for Rural Development, 23(127).

Pariselle, A., Lim, L., \& Lambert, A. (2001a). Monogeneans from Pangasiidae (Siluriformes) in Southeast Asia: I. Five new species of Thaparocleidus Jain, 1952 (Ancylodiscoidinae) from Pangasius pangasius, $P$. kinabatanganensis, $P$. rheophilusand, $P$. nieuwenhuisii. Parasite, 8(2), 127-135.

Pariselle, A., Lim, L., \& Lambert, A. (2001b). Monogeneans from Pangasiidae (Siluriformes) in Southeast Asia: II. Four new species of Thaparocleidus Jain, 1952 (Ancylodiscoidinae) from Pangasius 
humeralis. $\quad$ Parasite, $\quad$ 8(4), 317-324. doi:10.1051/parasite/2001084317

Pariselle, A., Lim, L., \& Lambert, A. (2002). Monogeneans from Pangasiidae (Siluriformes) in Southeast Asia: III. Five new species of Thaparocleidus Jain, 1952 (Ancylodiscoididae) from Pangasius bocourti, $P$. djambaland P. hypophthalmus. Parasite, 9(3), 207217. doi:10.1051/parasite/2002093207

Pariselle, A., Euzet, L., \& Lambert, A. (2004). Monogeneans from Pangasiidae (Siluriformes) in Southeast Asia: VI. Pangasitrema camillaen. (Monogenea, Ancylodiscoididae), from Pangasius polyuranodon. Parasite, 11(2), 149-152. doi:10.1051/parasite/2004112149

Pariselle, A., Lim, L., \& Lambert, A. (2006). Monogeneans from Pangasiidae (Siluriformes) in Southeast Asia: X. Six new species of Thaparocleidus Jain, 1952 (Ancylodiscoididae) from Pangasius micronema. $\quad$ Parasite, 13(4), 283-290. doi:10.1051/parasite/2006134283

Pouyaud. L., Deveney. M., \& Pariselle. A. (2006). Phylogenetic relationships among monogenean gill parasites (Dactylogyridea, Ancyrocephalidae) infesting tilapiine hosts (Cichlidae): systematic and evolutionary implications. Molecular Phylogenetics and Evolution, 38(1): 241-249.

Poulin, R. (1992). Determinants of host-specificity in parasites of freshwater fishes. International Journal for Parasitology, 22(6), 753-758.

Reed, P., Francis-Floyd, R., Klinger, R. E. (2009). Monogenean parasites of fish. Fisheries and Aquatic Sciences. University of Florida UF, IFAS Extension. FA28, USA. pp 1-4.

Roberts, T. R., \& Vidthayanon, C. (1991). Systematic revision of the Asian catfish family Pangasiidae, with biological observations and descriptions of three new species. Proceedings of Academy of Natural Sciences Philadelphia, 143, 97-144.

Rohde, K. (1979). A critical evaluation of intrinsic and extrinsic factors responsible for niche restriction in parasites. American Naturalist, 114, 648-671.

Rohde, K. (2005). Marine parasitology. Australia: CSIRO Publishing, pp. 189-196.

Shariff, M. (1984). Penyakit Ikan,: Pengenalan, cara-cara pengawalan dan rawatan. Kementerian Pertanian Malaysia . $48 \mathrm{p}$.
Šimková, A., Serbielle, C., Pariselle, A., Vanhove, M. P., \& Morand, S. (2013). Speciation in Thaparocleidus (Monogenea: Dactylogyridae) Parasitizing Asian Pangasiid Catfishes. BioMed Research International, 114. doi: $10.1155 / 2013 / 353956$

Snieszko, S. F. \& Axelord, T. (1980). The prevention and treatment of diseases of warm water fish under subtropical condition with special emphasis on intensive fish farming. Diseases of fish Book 3, T. F. H. Publication, Inc. Neptune city, New Jersey, USA.

Thomas, F., Brown, S.P., Sukhdeo, M. and Renaud, F. (2002). Understanding parasite strategies: a state dependent approach?. Trends in Parasitology 18: 387390.

Thompson, R.C.A., Lymbery, A.J., \& Smith, A. (2010). Parasites, Emerging Disease and Wildlife Conservation. International Journal for Parasitology., 40(10), 1163-1170. doi:10.1016/j.ijpara.2010.04.009.

Wu, X. Y., Zhu, X. Q., Xie, M. Q., Wang, J. Q., \& Li, A. X. (2008). The radiation of Thaparocleidus (Monogenoidea: Dactylogyridae: Ancylodiscoidinae): phylogenetic analyses and taxonomic implications inferred from ribosomal DNA sequences. Parasitology Research, 101(2), 283-288. 